\title{
Editorial
}

\section{Social determinants of child health and wellbeing}

Jianghong $\mathrm{Li}^{1}$, Eugen Mattes ${ }^{2}$, Anne McMurray ${ }^{3}$, Clyde Hertzman $^{4}$, Fiona Stanley ${ }^{2}$

1. Centre for International Health and School of Public Health, Curtin University of Technology

2. Telethon Institute for Child Health Research, Centre for Child Health Research, University of Western Australia

3. School of Nursing \& Midwifery, Murdoch University, Australia

4. Human Early Learning Partnership, University of British Columbia

Citation: Li, Jianghong and Mattes, Eugen and McMurray, Anne and Hertzman, Clyde and Stanley, Fiona. 2009. Social determinants of child health and wellbeing. Health Sociology Review 18 (1): pp. 3-11. 


\begin{abstract}
This Editorial provides a critical review of the progress in social determinants of health research over the last two decades, suggesting new perspectives which may further our understanding of persistent social inequalities in health. It highlights the global significance of the Special Issue setting it in the context of the recently released WHO Commission on Social Determinants of Health Final Report (CSDH 2008). The Editorial introduces individual papers in the Special Issue and discusses how they are in line with, complement or provide feedback to, the WHO CSDH Final Report and its call for actions to close the health gap in a generation. Finally, based on the articles in this Special Issue and emerging themes of the global research and policy literature, it outlines a number of significant directions for future research and actions, from both methodological and theoretical points of view.
\end{abstract}

Key words: child health and development, health inequity, social determinants, social gradient, intervention, Indigenous health, sociology. 


\section{Introduction}

Strong associations between socioeconomic status, measured by such factors as level of education, income, and occupational status, greater access to resources and political power, and an individual's health and wellbeing are well established and evident throughout the whole life course. Clearly, social factors are fundamental elements of the causal pathways to ill health and disease (Link and Phelan 1995; Marmot and Wilkinson 1999; CSDH 2008) and indirectly through their impact on early child development. Hence they also influence our current and future wealth (Keating and Hertzman 1999). With the growing evidence of the impact of social inequalities on health, policy makers in all countries are showing an increased interest in understanding them and in seeking ways to create more equitable societies. The importance of this trend is charted in two editions of "Social Determinants of Health" by Michael Marmot and Richard Wilkinson (1999; 2006), the establishment of the Commission on the Social Determinants of Health (CSDH) by the World Health Organisation (WHO), the CSDH Final Report (CSDH 2008), governmental initiatives to tackle health inequalities (The UK Department of Health 2005; EUROTHINE 2007; the Ministry of Social Affairs and Health - Helsinki Finland 2008; The UN Special Rapporteur 2008) and the proliferation of scholarly publications on social inequity in health in leading journals, such as the Lancet, British Medical Journal, Social Science and Medicine, The New England Journal of Medicine, the International Journal of Epidemiology, American Journal of Public Health and Journal of Epidemiology and Community Health.

Research on the social determinants of health has moved beyond the initial stage of simplistic descriptions of diseases and illness patterns by socio-economic status (Townsend and Davidson 1982; Acheson et al 1998; Marmot et al 1991; Marmot and Wilkinson 1999, to cite just a few) to a quest for deeper knowledge of what might be the complex mechanisms that underpin the commonly observed social disparities and gradients in health from both theoretical and empirical approaches (Berkman and Kawachi 2000; Kelly et al 2006; Eckersley et al 2001; Spencer 2006; Thrane 2006). While it is accepted that social gradients and disparity in health are universal and strong, there is less agreement as to what might explain them. Three dominant perspectives offering different explanations exist (Thrane 2006; Turrell 2001; Taylor 2001; Raphael 2002): materialistic explanations, psychosocial perspectives (Marmot and Wilkinson 1999; Marmot 2004; Kawachi et al 1997; 1999) and life style explanations.

According to the materialistic explanations, social disparities and gradients in health stem from differential access to economic and social resources that enable healthy living, and to preventive and curative health care, and differential exposures to occupational hazards and unhealthy living environments. The psychosocial explanation emphasises social support, social capital and perceived and relative income inequality as the main causes of health inequality. The life style perspective sees different life style choices individuals make, such as smoking, drinking, diet and exercise, as the primary causes of health inequality (see Raphael 2002; Thrane 2006 for a review). By themselves, none of these explanations alone can adequately explain the pervasive health inequality so consistently evident cross time and space. The social, economic and behavioural factors highlighted in each of these 
perspectives may jointly influence, mediate or moderate each other to produce health inequality and there is emerging research that attempts to combine them (Thrane 2006).

However, much of the literature on the social determinants of health still lacks a common structural approach to explain universally observed health inequity. Whilst there is some research on the link between childhood social and economic circumstances and adult morbidity and mortality (Davey Smith et al 2001; Osler et al 2003; Pulton et al 2002; Hayward and Gorman 2004), most focus primarily on adult health. The need to focus on infancy and childhood is paramount, given that increasing evidence from developmental health research suggests that the early years of development play a vital role in creating and maintaining socioeconomic health inequalities through to adulthood (Keating and Hertzman 1999). From a pathway approach, early development from conception to five years of age is widely accepted as establishing the foundation for learning, behaviour and health throughout the life cycle (Keating and Hertzman 1999; McCain and Mustard 1999). It may also have an inter-generational influence on health and wellbeing. The "biological embedding" process occurring in early life (Keating and Hertzman 1999:1) and early socialisation (Singh-Manoux and Marmot 2005; Kendal and Li 2005) that transmits health enhancing values and behaviours from parents to offspring offers insights into how health inequality begins in early childhood, persists into adulthood and acts across generations. Interactions among genetic, psychological and social influences may also be important. These perspectives deserve greater attention in future inquiry about causes of persistent social inequality in health.

For many years, the global community has been aware of the importance of research and policy development related to the social contexts of child health, particularly in impoverished nations. Today the concerns with social environments for children's health have also been brought into clear focus in countries of the West, particularly given the evidence of poor outcomes for today's children and youth (Keating and Hertzman 1999; McCain and Mustard 1999; The World Bank 2006; Stanley et al 2005; The UNICEF Innocenti Research Centre 2007; Li et al 2008; CSDH 2008; ARACY Report Card October 2008). These issues are also rapidly becoming of greater relevance to medium and low income countries as their economies change. This is reflected in the engagement and support of the World Bank, WHO, UNICEF and OECD encouraging governments of developing countries to promote early child development as an international goal to enhance human capital. However, the current global economic recession could pose a major threat to these concerted efforts to promote child development worldwide.

Recently, the release of the WHO Commission on Social Determinants of Health Final Report calls for closing the health gap in a generation. The Report outlines three principles of action to reduce health inequity: "Improve daily living conditions; Tackle the inequitable distribution of power, money, and resources; Measure and understand the problem and assess the impact of action" (CSDH 2008: 2). The Report emphasises investments in early child development and education as "powerful equalizers" and calls for a more comprehensive approach to understanding early child development, and to early childhood interventions (CSDH 2008: 50-59). 
We welcome this well deserved recognition of the critical role early child health and development plays perpetuating health inequity in adult populations.

It is also pleasing to see that in more recent years, there is an increasing recognition of the need for a structural approach to provide a deeper understanding of the "fundamental causes" of health inequity and to actions aimed at reducing it. Instead of solely focusing on individual socioeconomic status (eg, education, occupation and income), individual psychosocial attributes (eg, social capital, social connectedness, perceived inequality) and neighbourhood characteristics, this new perspective looks into the macro forces that ultimately drive the social determinants of health and profound social injustice and health inequity. These include the nature of the dominant political economy and neo-liberalisms (Coburn 2004; Li et al 2008), the welfare state (Chung and Muntaner 2006; Bambra and Eikemo 2009) and globalisation and its consequences for health inequity (Labonte et al 2005; Waitzkin et al 2005; CSDH 2008: 110-144).

\section{This special issue}

In line with, and to complement the WHO CSDH Final Report, this Special Issue presents nine innovative papers that address social determinants of child health and wellbeing from unique perspectives, using both qualitative and quantitative methods. These papers have been accepted for publication following a process of anonymous and rigorous reviews by international experts in the relevant areas. Concomitant with the Final Report's third principle of action on closing the health gap in a generation: "Evaluate Action", four papers of this special edition focus on topics related to interventions to reduce health inequity in children and adolescents from different, important angles (Judge 2009; Katz and Redmond 2009; Kavanagh et al 2009; Pike and Colquhoun 2009).

Judge (2009) examines variations in policy responses to perceptions of social inequities in infant mortality in Canada, Chile, Sweden and the United Kingdom. These countries were chosen to work together as country partners to support the World Health Organisation's Commission on Social Determinants of Health. The author highlights the weakness of the evidence base for assessing the effectiveness of interventions that aim at reducing inequalities in infant mortality in these four countries and that this problem may be even bigger elsewhere and relevant to other areas of intervention.

Kavanagh et al (2009) reports the findings of a systematic review of the effectiveness of school-based interventions using cognitive behavioural therapy (CBT) for preventing depression amongst young people aged 11-19. The authors apply an 'equity lens' in their systematic review to examine whether intervention effectiveness is influenced by socioeconomic status (SES) or other sociodemographic factors implicated in the emergence of health inequalities. Similar to the findings reported by Judge (2009), Kavanagh and her co-authors point out that the biggest hurdle in applying an equity lens in evaluations of impact was the general lack of sociodemographic data in intervention studies. These findings, together with the results reported by Judge, are useful and timely feedback to the CSDH call for evaluations for actions to reduce health inequity. They suggest that as we move to the phase of interventions to redress health inequity, we must not forget that there is 
a critical need for a stronger and more robust empirical base for assessing the impact of actions.

The paper by Pike and Colquhoun (2009) presents findings from an evaluation of an innovative intervention scheme, called the 'Eat Well Do Well' programme in Kingston-upon-Hull, UK. The authors have shown that school can serve as a powerful platform for implementing actions to reduce social disparities in nutritional intake by way of universal provision of free and healthy school meals for all primary school children. Such an intervention has the potential to reduce health gradients and inequity by improving nutrition across the population and has implications for other countries, particularly countries with large proportions of disadvantaged children with barriers to accessing healthy and nutritious food. The authors also suggest that school specific contexts, such as the spatial arrangement of the dinning environment and how the free schools meals are delivered must be taken into consideration when developing such interventions, as these factors can either enhance or weaken the impact of well-intended programmes.

Katz and Redmond address an important policy issue: how much governments invest on children of different ages and what the optimum investment in the early years would look like. The authors have explored two ways in which public expenditure on children in their early years can be measured by making international comparisons and examining trends in Australia over times. The authors found that while Australia spends more than the average of OECD countries on the early years, much of this expenditure is spent on cash transfers to parents rather than directly on early care and education. Yet it is the quality of early care and education that has been shown to be powerful predictors of human development outcomes (Kohen et al 2002). For example, children born in poverty who participated in a high quality preschool program have higher social responsibility, educational performance, earning and property wealth and greater commitment to marriage when they enter into adulthood (Hill et al 2004). These findings beg the question: what is the optimal balance between direct investments which are used at the discretion of families compared with investments in services and institutions which families can access. The challenge is to find the best mix of both approaches which may vary depending on the social and other diversity of the populations being served. One approach is to conduct careful cross-national comparisons of policies using indicators of child health and wellbeing, calling yet again for more fine grained data and analyses to address this important question.

This edition also complements the CSDH Final Report with two papers that focus on the mental health and wellbeing of adolescents in the US and Australia (Han and Miller 2009; Williams et al 2009). Adolescence is an equally important period of human development as adolescents face greater challenges than younger children in terms of their changing identities, social relationships, sexuality, risky behaviours, education and taking on adult work roles (Lawrence 2005; Dockery et al in press). A focus on adolescents is also crucial to address their future parental roles and the inter-generational influences of disparity and child outcomes.

Using the National Longitudinal Survey of Youth-Child Supplement (NLSY-CS) in the US, and advanced analytical methods, Han and Miller examine the relationship 
between parental work schedules and adolescent depression at age 13 or 14, with a focus on the mechanisms that may explain this relationship. The authors found that regular night shifts by mothers and evening work by fathers were associated with a lower quality of home environment, fewer meals together and lower paternal closeness, which in turn lead to increased risks for adolescent depression. This is a very important and timely study as we live in an increasingly market driven economy and work-oriented society. It also highlights parental work as an important yet a neglected social determinant of child health (Strazdins et al 2004; 2006; Dockery et al in press).

The paper by Williams et al. (2009) addresses the question of how teenagers live their lives within the spatial and temporal limitations imposed by an 'adult' world, in the context of changing work and household patterns in Australia. This is an innovative qualitative study in canvassing the views of a large number of teenagers (174) aged between 11 and 18 years, recruited from both state and private schools servicing communities and three traditional lower socio-economic status suburbs in South Australia, Victoria and Queensland. The authors found that more teenagers from homes with fewer amenity and mobility resources rely on community resources being adequate to gain access to opportunity than teenagers from better resourced homes. The study showed that the voices of teenagers describe a society that marginalises adolescents. The findings point to the importance of inter-sectoral coherence in policy (transport, work place, school and communities) to address the emotional wellbeing of adolescents.

This special issue further contributes to our understanding of social determinants of child health with two papers that examine social determinants of child health and wellbeing from legal and historical perspectives. Sweet and Power (2009) underline the fact that the law as a structural determinant of child health and wellbeing has not been addressed in previous research. Using breastfeeding and the Shared Parental Responsibility Act 2006 as an example, the authors make the important point that court decisions can work at a macro-level to produce social and health disparities for affected children. This legal perspective is also useful for investigating other important outcomes of child health and wellbeing, such as child abuse and neglect and domestic violence against children and women.

The paper by Janet McCalman (2009) offers us a historical insight into the link between societal change and changes that occurred at the family level and the health and well being of children in Australia and England. The author argues that since the 1970s neo-liberalism and consequent societal obsession with a pursuit of affluence and individualism has led to some of the adverse child outcomes in today's developed economies, such as child obesity. This paper joins other scholars in searching for answers to the 'modernity's paradox': Why are we witnessing a decline in indicators of human development and rising social inequalities, despite postmodern society's unprecedented economic prosperity and medical and technological advancement (Hertzman 1999; Stanley et al 2005; Li et al 2008).

Cheryl Kickett-Tucker (2009) explores how the racial identity of Australian Aboriginal children and youths can be defined and operationalised using qualitative data. She finds that cultural identify self identity is the most salient element of racial identity. Racial identity is important as it has been linked to Indigenous mental health, possible through its interaction with racism 
to influence health in either a positive or a negative way: racism experienced by Aboriginal children and youths poses a threat to the maintenance of their racial identity but the development of a strong racial identity can buffer the detrimental impact of racisms on mental health.

\section{Implications for future research and interventions}

We intended this special issue as a provocative stimulus for further research and policy work. It is therefore with pleasure that we launch this edited volume, and hope that it creates a dialogue on the social determinants of child health that will engage researchers, students, health practitioners and policy-makers. Based on the articles in this Special Issue and emerging themes of the research and policy literature, we envision a number of significant directions for future research and actions, from both methodological and conceptual and theoretical point of views.

The social determinants of health agenda must be extended to integrate alternative methodologies with the predominantly quantitative approach for capturing the contextual elements in children's health and development. For example, there is a need to extend our research agenda using interpretive, qualitative methods, such as action research and the kind of methodological approaches used in the study of adolescents and children (Kickett-Tucker 2009; Williams et al 2009; Pike and Colquhoun 2009) to hear people's voices as a basis for acting on local knowledge and for improving children's health. Such meaningful, contextualised information should be integrated into our evidence-based agenda in what has been called the "primacy of the practical" (Sandelowski 2004:1367). This is in line with the recommendations of the CSDH (2008).

Given the pervasive impact of socioeconomic status (SES) on health and the fact that many aspects of this influence are amenable to policy intervention, especially at the macro-level (such as universal education), unless justified, all studies of population health should include robust measures of the current socioeconomic status of its participants. The increasing evidence for intergenerational and early life impacts on adult health underscores a growing need to include measures of socioeconomic status from the previous generation and of the participants' childhood. Information on individual level socioeconomic status should also be included in the routine population level data collections, such as existing linked administrative data bases for health, education, child protection and crime in Western Australia as an example (Glauert et al 2008). Such information will greatly enhance the power of these databases for unpacking and monitoring social gradients of health and evaluating actions to redress them.

The lack of published research enabling robust meta-analyses of the role of social gradients in the outcomes of health interventions highlights not only the aforementioned need to include such data in research but also a need to assess and address the underlying biases in research funding and in publication. The funding and resultant publication bias towards pharmaceutical related biomedical versus social research is one such example. As Prinja and Kumar (2009) point out, the pharmaceutical industry is one of the most powerful interest groups that influence health policies in most countries but these groups are least affected by health 
inequity. The revenue of the top ten global pharmaceutical companies outnumbers the gross national income of the 57 lowest-income countries (Prinja and Kumar 2009). It remains a great challenge to realise the aim of the WHO CSDH to "close the gap in a generation" without social change. Educational equality is a fundamental determinant of health equity. Investment in educational attainment versus heavy investment in medical advances can lead to a massive reduction of mortality at a ratio of 8:1 (Woolf et al 2007). Hence tackling educational inequity should be a starting point for actions to fundamentally reduce health inequity.

One of the greatest challenges is to address health inequalities outside the realms of health services: not only in communities but also within schools, the workplace and the law. This series of papers further highlights the importance of cross jurisdictional data linkage for whole populations and also an integration of individual and structural perspectives, and within individual approaches a combination of social, biological and psychological insights to further our knowledge of pathways to social inequity in health and to develop and evaluate intervention schemes.

The social determinants of health research agenda must also address profound health disparities between the mainstream children and Indigenous children and those from culturally and linguistically diverse backgrounds (CALD) at both national and international level. From both scientific and policy point of views, it will be interesting and important to see if the social gradients of health universally observed in the non-Indigenous populations also exist in Indigenous populations and whether there is alternative conceptualisation of "social determinants" in indigenous and CALD contexts. Racial identity and racism deserved much greater attention in social determinants of health research in Indigenous and CALD contexts.

The notion of "human rights to health" is gaining increasing recognition in research and few would disagree with this social justice principle and ideal. But it is time to think of how these rights can be guaranteed and protected in concrete terms and there is a critical need to begin cross-disciplinary dialogues between health, law, politics and health economics to map out the path to reaching this goal. 


\section{References}

Acheson, D.; Barker, D.; Chambers, J.; Drever, F.; Earwicker, R.; Graham, H.; Law, C.; Marmot, M. and Whitehead, M. (1998) Independent Inquiry Into Inequalities In Health Report The Stationery Office, Norwich: UK.

ARACY (2008) Report Card: The Wellbeing of Young Australians. Available at: http://www.aracy.org.au/AM/Common/pdf/report card/report card A5 web.pdf [Date of access: 09.02.09].

Bambra, C and Eikemo, T.A. (2009) 'Welfare state regimes, unemployment and health: A comparative study of the relationship between unemployment and selfreported health in 23 European countries' Journal of Epidemiology and Community Health 63:92-98.

Berkman, L.F. and Kawachi, I. (2000) Social Epidemiology, Oxford: Oxford University Press.

Chung, H. and Muntaner, C. (2006) 'Political and welfare state determinants of infant and child health indicators: An analysis of wealthy countries' Social Science \& Medicine 63:829-842.

Coburn, D. (2004) 'Beyond the Income Inequality Hypothesis: Class, Neo-liberalism, and Health Inequalities' Social Science \& Medicine 58:41-56.

CSDH (2008) Closing the Gap In A Generation: Health Inequity Through Action On The Social Determinants Of Health. Final Report of the Commission on Social Determinants of Health World Health Organisation: Geneva.

Davey Smith, G.; Gunnell, D. and Ben Shlomo, Y. (2001a) 'Life-course approaches to socio-economic differentials in cause-specific adult mortality' in Leon, D. and Walt, G. (eds) Poverty, Inequality And Health Oxford University Press: Oxford, England, pp.88-124.

Dockery, M.; Li, J. and Kendall, G. (In press) 'Parents work patterns and adolescent health and wellbeing' Social Science \& Medicine.

Eckersley, R.; Dixon, J. and Douglas, B. (2001) The Social Origins Of Health And Wellbeing Cambridge University Press: Cambridge, the UK.

EUROTHINE (2007) Tackling Health Inequalities in Europe: An Integrated Approach, Final Report, Department of Public Health, University Medical Center Rotterham: The Netherlands. Available at: http://ec.europa.eu/health/ph projects/2003/action1/docs/2003116 frep en.pdf [Date of access: 28.10.09].

Glauert, R.; Li, J.; Hagemann, E.; de Klerk, N.; The Developmental Pathways Project Team; The Data Linkage Unit Team; Fiona, S. (2008) Novel data linkages for child and youth developmental pathways: Using agency data from health, education, child protection, disability services and justice in Western Australia, The Developmental 
Pathways Project working paper, Telethon Institute for Child Health Research: Perth, Western Australia.

Han, W.-J., and Miller, D.P. (2009) 'Parental work schedules and adolescent depression' Health Sociology Review 18(1):

Hayward, M.D. and Gorman, B.K. (2004) 'The long arm of childhood: The influence of earlylife social conditions on men's mortality' Demography 41:87-107.

Hill, Z.; Kirkwood, B. and Edmond, K. (2004) Family And Community Practices That Promote Child Survival, Growth And Development: A Review Of Evidence, World Health Organisation: Geneva.

Judge, K. (2009) 'Inequalities in infant mortality: Patterns, trends, policy responses and emerging issues in Canada, Chile, Sweden and the United Kingdom' Health Sociology Review 18 (1):

Katz, I. and Redmond, G. (2009) 'Investment in early childhood in Australia: international comparisons and recent trends' Health Sociology Review 18(1):

Kavanagh, J; Oliver, S.; Lorenc, T.; Caird, J.; Tucker, T.; Greaves, A.; Harden, A.; Oliver, K.; Thomas, J. and Oakley, A. (2009) 'School-based cognitive-behavioural interventions: A systematic review of effects and inequalities' Health Sociology Review 18(1):

Kawachi, I.; Kennedy, B.P.; Lochner, K. and Prothrow-Stith, D. (1997) 'Social capital, income inequality, and mortality' American Journal of Public Health 87 (9):1491-1498.

Kawachi, I.; Kennedy, B.P. and Glass, R. (1999) 'Social capital and self-rated health: a contextual analysis' American Journal of Public Health 89 (8):1187-1193.

Keating, D. and Hertzman, C. (1999) Developmental Health And The Wealth Of Nations. Guildford Press: New York.

Kelly, M.P.; Bonnefoy, J.; Morgan, A. and Florenzano, F. (2006) The Development of the Evidence Base about the Social Determinants of Health. WHO Commission on Social Determinants of Health, Measurement and Evidence Knowledge Network: Geneva.

Kendall, G. and Li, J. (2005) 'Response to "Role of socialization in explaining social inequalities in health" by Archana Singh-Manoux and Michael Marmot (Social Science \& Medicine, 2005; 60: 2129-2133)' Social Science \& Medicine 61: 2272-2276.

Kickett-Tucker, C. (2009) 'Moorn (Black)? Djardak (White)? How come I don't fit in Mum? Exploring the racial identity of Australian Aboriginal children and youths Health Sociology Review 18(1):

Kohen, D.; Hertzman, C. and Willms, J.D. (2002) 'The importance of quality child care' in Willms, J. (ed) Vulnerable Children: Findings From Canada's National 
Longitudinal Survey Of Children And Youth The University of Alberta Press: Edmonton, pp. 261-276.

Labonte, R.; Schrecker, T. and Gupta, A. S. (2005) Health for Some: Death, Disease and Disparity in a Globalizing Era, Centre for Social Justice Research and Education: Toronto.

Lawrence, J. (2005) 'Young people in transition: Challenges and opportunities for contemporary Australian youth' in Richardson, S. and Prior, M (eds) No Time To Lose: The Wellbeing Of Australia's Children Melbourne University Press: Melbourne, pp.281-297.

Link, B.G. and Phelan, J.C. (1995) 'Social conditions as fundamental causes of disease' Journal of Health Social Behaviour (Extra Issue):80-94.

Li, J.; McMurray, A. and Stanley, F.J. (2008) "Modernity's paradox and the structural determinants of child health and well-being' Health Sociology Review 17:64-77.

Marmot, M.G. and Wilkinson, R.G. (1999) Social Determinants Of Health (1st edition) Oxford University Press: Oxford.

Marmot, M.G. and Wilkinson, R.G. (2006) Social Determinants Of Health (2nd edition) Oxford University Press: Oxford.

Marmot, M.G. (2004) The Status Syndrome: How Does Social Standing Affect Our Health and Longevity? Times Books: New York.

Marmot, M.G.; Davey Smith, G. and Stansfeld, S.A. (1991) 'Health inequalities among British civil servants: The Whitehall II study' Lancet 337:1387-93.

McCain, M. and Mustard, J.F. (1999) Early Years Study: Reversing The Brain Drain. Available

at : http://www.founders.net/ey/home.nsf/a811f0e8afbb2a7985256786003a3dd9/1e4 ad2a677be034685256a4700737a3b/\$FILE/early years study.pdf [Date of access:16 01.09].

McCalman, J. (2009) 'Silent witnesses: child health \& wellbeing in England and Australia and the health transition 1870-1940' Health Sociology Review 18 (1):

Osler, M.; Anderson, A.M.; Due, P.; Lund, R.; Damsgaard, M.T. and Holstein, B.E. (2003) 'Socioeconomic position in early life, birth weight, childhood cognitive function, and adult mortality: A longitudinal study of Danish men born in 1953' Journal of Epidemiology and Community Health 57:681-86.

Pike, J. and Colquhoun, D. (2009) 'The relationship between policy and place: The role of school meals in addressing health inequalities' Health Sociology Review 18(1):

Poulton, R.; Caspi, A.; Milne, B.; Thomson, W.; Taylor, A.; Sears, M. and Moffitt, T. (2002) 'Association between children's experience of socioeconomic disadvantage and adult health: A life-course study' Lancet 360:1640-1645. 
Prinja, S. and Kumar, R. (2009). 'Reducing health inequities in a generation: A dream or reality?' Bulletin of the World Health Organization 87:84-84.

Raphael, D. (2002) Social Justice is Good for Our Hearts: Why Societal Factors, Not Lifestyles, are Major Causes of Heart Disease in Canada and Elsewhere Centre for Social Justice, CSJ Foundation for Research and Education: Toronto, Canada.

Sandelowski, M. (2004) 'Using qualitative research' Qualitative Health Research 14:1366-1386.

Singh-Manoux, A. and Marmot, M. (2005) 'Role of socialization in explaining social inequalities in health' Social Science \& Medicine 60:2129-2133.

Spencer, N. (2006) 'Explaining the social gradient in smoking in pregnancy: Early life course accumulation and cross-sectional clustering of social risk exposure in the 1958 British national cohort' Social Science \& Medicine 62:1250-1259.

Stanley, F.; Richardson, S. and Prior, M. (2005) Children Of The Lucky Country? How Australian Society Has Turned Its Back On Children And Why Children Matter! Pan MacMillan: Sydney.

Strazdins, L.; Korda, R.J.; Lim, L. L-Y.; Broom, D.H. and D'Souza, R.M. (2004) 'Around-the-clock: Parent work schedules and children's well-being in a 24-h economy' Social Science \& Medicine 59:1517-1527.

Strazdins, L.; Clements, M.S.; Korda, R.J.; Broom, D.H. and D'Souza, R.M. (2006) 'Unsocialised Work? Nonstandard work schedules, family relationships, and children's wellbeing' Journal of Marriage and Family 68:394-410.

Sweet, L. and Power, C. (2009) 'Family Law as a determinant of child health and welfare: Shared parenting, breastfeeding and the best interests of the child' Health Sociology Review 18(1):

Townsend, P. and Davidson, N. (1982) Inequalities In Health Penguin Books: London.

Taylor, R. (2001) 'Mediation of the effects of social and economic status on health and mortality: The role of behaviour and constitution' in Eckersley, R.; Dixon, J. and Dougals, B. (eds) The Social Origins Of Health And Wellbeing, Cambridge University Press: Cambridge, the UK, pp.105-113.

The Ministry of Social Affairs and Health - Helsinki FINLAND (2008) National Action Plan to Reduce Health Inequalities 2008-2011, Publications of the Ministry of Social Affairs and Health - Helsinki FINLAND 2008. Available at: http://www.stm.fi/Resource.phx/publishing/store/2008/11/pr1227003636140/passt hru.pdf [Date of access: 27.12.08].

The UK Department of Health (2005) Tackling Health Inequalities: Status Report on the Programme for Action. Available 
at: http://www.dh.gov.uk/assetRoot/04/11/76/98/04117698.pdf [Date of access:16.01.09].

The UN Special Rapporteur on the Right to the Highest Attainable Standard of Health: Looking Back and Moving Forward International Symposium. Available at: http://www.humanrightsimpact.org/fileadmin/hria resources/HeRWAI Centre/Report SRRH Symposium 25-27 September 2008.pdf [Date of access: 27.12.08].

The UNICEF Innocenti Research Centre (2007) An Overview of Child Well-being in Rich Countries: A Comprehensive Assessment of the Lives and Well-being of Children and Adolescents in the Economically Advanced Nations The United Nations Children's Fund (UNICEF): Florence.

The World Bank (2006) World Development Report 2006: Equity And Development Oxford University Press: New York.

Thrane, C. (2006) 'Explaining educational-related inequalities in health: Mediation and moderator models' Social Science \& Medicine 62:467-478.

Turrell, G. (2001) 'Income inequality and health: In search for fundamental causes' in Eckersley, R.; Dixon, J. and Dougals, B. (eds) The Social Origins Of Health And Wellbeing Cambridge University Press: Cambridge, the UK, pp.83-104.

Waitzkin, H.; Jasso-Aguilar, R.; Landwehr, A. and Mountain, C. (2005) 'Global trade, public health, and health services: Stakeholders' constructions of the key issues' Social Science \& Medicine 61: 893-906.

Williams, P.; Pocock, B. and Bridge, K. (2009) 'Kids lives in adult space and time: How home, community, school and adult work affect opportunity for teenagers in suburban Australia' Health Sociology Review 18(1):

Woolf, S.H.; Johnson, R.E.; Phillips, R.L.; Philipsen, M. (2007) 'Giving everyone the health of the educated: An examination of whether social change would save more lives than medical advances' American Journal of Public Health 97(4):679-683. 